[11] Mancia, G., Fagard, R., Narkiewicz, K., Redón, J., Zanchetti, A., Böhm, M. et. al. (2013). ESH/ESC Guidelines for the management of arterial hypertension: the Task Force for the management of arterial hypertension of the European Society of Hypertension (ESH) and of the European Society of Cardiology (ESC). Journal of Hypertension, 31 (7), $1281-1357$. doi: http://doi.org/10.1097/01.hjh.0000431740.32696.cc

[12] Unifikovanyi klinichnyi protokol pervynnoi, ekstrenoi ta vtorynnoi (spetsializovanoi) medychnoi dopomohy. Arterialna hipertenziia (2012). Nakaz Ministerstva okhorony zdorovia No. 384. 24.05.2012. Kyiv, 72.

[13] Gurses, K. M., Yalcin, M. U., Kocyigit, D., Canpinar, H., Evranos, B., Yorgun, H. et. al. (2015). Effects of Persistent Atrial Fibrillation on Serum Galectin-3 Levels. The American Journal of Cardiology, 115 (5), 647-651. doi: http://doi.org/10.1016/ j.amjcard.2014.12.021

[14] Clementy, N., Piver, E., Benhenda, N., Bernard, A., Pierre, B., Siméon, E. et. al. (2014). Galectin-3 in patients undergoing ablation of atrial fibrillation. IJC Metabolic \& Endocrine, 5, 56-60. doi: http://doi.org/10.1016/j.ijcme.2014.10.003

\title{
POSSIBILITIES OF USING MINIINVASIVE CATHETER TECHNOLOGIES IN THE TREATMENT OF LUNG BLEEDING
}

\author{
Kateryna Ponomarova \\ Department of Thoraco-Abdominal Surgery \\ V. T. Zaytsev Institute of General and Emergency Surgery of NAMS of Ukraine \\ 1 Balakireva entry, Kharkiv, Ukraine, 61018 \\ eponkat@gmail.com
}

\footnotetext{
Abstract

Aim - improve the results of the treatment of patients with pulmonary bleeding through widespread use of endovascular surgery methods for hemostasis.

Materials and methods. Method of endovascular embolization of bronchial arteries is widely used in our clinic SI «Zaycev V. T. Institute of General and Emergency surgery of NAMS of Ukraine» not only as independent surgery in patients with LB, but also as way of preparation of patients with lung bleeding for planned thorax surgery. The most of the often spread nosological forms complicated by bleeding in our research were polycystic lung disease, chronic obstructive pulmonary disease, bronchiectasis disease, community-acquired pneumonia. Indications to the catheter embolization procedure of bronchial arteries are the following: conservative treatment failure, hemoptysis in patients with bilateral inflammatory processes who was not prescribed surgical treatment for a range of reasons, absence of gross structural changes, lung resection, mainly in patients with oncologic lung injury, at massive and life-threatening profuse bleedings as a mean of temporary or constant hemostasis. Discussed treatment method is applied only in bleeding or within a 6-12 hour after its treatment. Successful result in embolization can be obtained in 79-99 \%.

Results. As a result of complete physical examination of patients with LB, it has been established that lung hemorrhage was the result of obstructive bronchitis in 14 patients (42\%), there was chronic obstructive pulmonary disease in 7 (21 \%) patients and bronchiectasis was diagnosed in $6(18 \%)$ patients. In $2(6 \%)$ patients pulmonary hemorrhage was caused by community-acquired pneumonia. Central lung cancer was detected in 4 (12\%) patients.

Conclusion. Therefore bronchial artery angiography gives high efficiency in solving the problem of hemostasis in oncological and nonspecific lung diseases, for determination of localization and source of bleeding. Endovascular occlusion of bronchial arteries in pulmonary hemorrhage permits:

- to elaborate diagnosis because of the presence of specific angiographic signs of malignant tumour;

- to perform effective endovascular hemostasis;

- to gain time for stabilization the patient with the aim of planned surgical treatment.

Keywords: embolization of bronchial arteries, hemostasis, pulmonary bleeding, catheter technologies.
}

DOI: $10.21303 / 2504-5679.2019 .001087$ 


\section{Introduction}

Treatment of pulmonary bleeding is still one of the most pressing problems in surgery. Pulmonary bleeding is the most dangerous complication of a number of diseases [1, 2]. There are 40 nosological forms that can be complicated by pulmonary hemorrhage ( $\mathrm{PH})$; some authors describe PH as a complication in more than 100 diseases [3, 4]. Over the last decade, the role of obstructive and purulent pulmonary diseases, which significantly suppressed pulmonary tuberculosis, has increased in the emergence of pulmonary bleeding (PB) $[5,6]$.

Pulmonary bleeding is often a complication of various respiratory system diseases that are associated with the inflammatory process, which are found in 8-17\% of hospitalized patients $[7,8]$. Most authors believe that in $95-98 \%$ of observations the source of pulmonary bleeding in patients is bronchial arteries, which depart from the aorta and pleura [9, 10]. A considerable amount of surgical remedies to combat this threatening complication often complicates the choice of optimal treatment tactics and leads to the expansion of indications for the further implementation of surgical interventions, which may adversely affect the expected results of treatment and rehabilitation of patients in the early and long periods [11]. Despite certain advances in surgical treatment of pulmonary hemorrhage, which is associated with the use in the treatment of endovascular technologies, the mortality rate is still quite high, according to various authors, ranges from $15.1 \%$ to $57.0 \%[12,13]$.

To date, X-ray vascular occlusion (REO) of the bronchial arteries allows patients to avoid surgery at the height of bleeding. Despite the fact that this method has been used in clinical practice for more than 30 years, the questions concerning the tactics of interventions and the choice of embolizing materials $[14,15]$. Efficiency of the method in the long-term period is devoted to the publications. In particular, in young patients, pulmonary hemorrhage may be the first sign of the disease, while the lungs may lack morphological changes in the lung tissue $[16,17]$.

Currently, a large number of researchers believe that urgent surgery should be performed at the height to PB in the absence of the effect of conservative treatment. X-ray vascular occlusion (REO) of the bronchial arteries allows patients to avoid surgery at the height to bleeding. A significant addition to the arsenal of methods of surgical treatment of pulmonary hemorrhage was made by intervention radiology. Among these treatments, traumatic X-ray and vascular interventions are becoming increasingly important [8].

The use of the achievements of interventional radiology and the use of modern endovascular catheter technologies in surgery in the late XX - early XXI centuries allowed to introduce a more advanced approach to the diagnosis and treatment of pulmonary bleeding [19]. Based on the level of development of interventional radiology in Ukraine, X-ray and vascular the rapies for the treatment of pulmonary hemorrhages of different etiology have not yet become widespread due to the lack of angiographic equipment in most clinics to provide highly qualified X-ray surgical care. The aim of the study. Improving the treatment of patients with pulmonary hemorrhage through widespread use of hemostasis for endovascular surgery [20, 21].

The aim of the research - improve the results of the treatment of patients with pulmonary bleeding through widespread use of endovascular surgery methods for hemostasis.

\section{Materials and methods}

The study was conducted at the Department of thoraco-abdominal surgery of SU

"Zaycev V. T. Institute of General and Emergency surgery of NAMS of Ukraine". We examined 81 patients with lung bleeding of different etiology, who were hospitalized in the Department of thoraco-abdominal surgery. All patients were divided into two groups - of the main group 45 patients and the comparison group 36 patients, depend of ages, sex, nosological form, level of lung bleeding. Patients aged from 25 to 82 years, including 51 men $(62.5 \%)$ and 30 women (37.5\%). The test diseases includes: bronchiectasis disease - in 29 (36.1\%), pulmonary fibrosis with malformation BA - in 30 (37.3\%), abscess of the lung - in 11 (13.1\%), polycystic lung disease - in $5(6.1 \%)$, chronic obstructive pulmonary disease - in $6(7.4 \%)$.

All patients were examined in accordance with the quality standards of the diagnostics. The diagnosis of the underlying disease was determined on the basis of general clinical examination, 
instrumental and laboratory methods. The clinical diagnostic criteria for LB included the check of hemoglobin level and blood pressure.

Roentgen-endovascular embolization of bronchial arteries was performed using and Phillips Integris Allura 12C (Holland). Bronchial artery angiography consists of the following: femoral catheterization was done by Seldinger technique under topical anesthesia $(0.25 \%$ solution of novocaine). Cateterization was performed by Cobra catheter with flexure $45-65$ degrees. Catheter was inserted at T4-T5 level under control of monitor and then it is fixed in the bronchial artery or intercostal artery mouth by rotational movement of guide. $1 \mathrm{ml}$ of contrast agent was added for monitoring of catheter location in required vessel. Polyurethane emboli having diameters of 450-720 mm were used for embolization. Emboli in combination with microembols were inserted at a big diameter of pathologically changed vessel that enhances effect of embolization. Absence of inflow of contrast agent and enhancement of distal part of bronchial arteries were considered as criteria of effective embolization.

Statistical comparisons were conducted using Student's t-test statistically significant at $\mathrm{p}<0.05$. Fisher's angular transformation. The calculations were performed using software STATISTICA for Windows and Microsoft Excel 10.0.

\section{Results}

Immediate positive full effect of REEBA in the form of a complete stop bleeding was observed in $78(89.8 \pm 1.2 \%, \mathrm{p} \leq 0.05)$ patients. Other authors perceived similar efficiency of endovascular hemostasis $[22,23]$. Late relapses of LB and blood coughing was observed in $17(20 \pm 2.1 \%$, $\mathrm{p} \leq 0.05$ ) of patients [24].

Treatment of patients was started from the hemostatic therapy: $5 \%$ solution of EACA, solution of sol. ethamsylati, dicynoni, sol. vicasoil, tranexamic acid. In patients with pulmonary hemorrhage of II grade, performed hemostatic therapy was added with introduction of albumin solution, fresh frozen plasma. Packed red cell transfusion was prescribed patients with pulmonary hemorrhage of III severity. Pulmonary hemorrhage was stopped in $14(42 \pm 2.9 \%, \mathrm{p} \leq 0.001)$ with the use of roentgen-endovascular hemostasis of bronchial arteries (Fig. 1). High efficiency of roentgen-endovascular occlusion in pulmonary hemorrhage of different etiology was noted by majority of authors. Recurrence of bleeding in the long period after REO appeared in $2(6.0 \pm 1.1 \%, p \leq 0.001)$ inoperable patients with bronchiectasis disease.

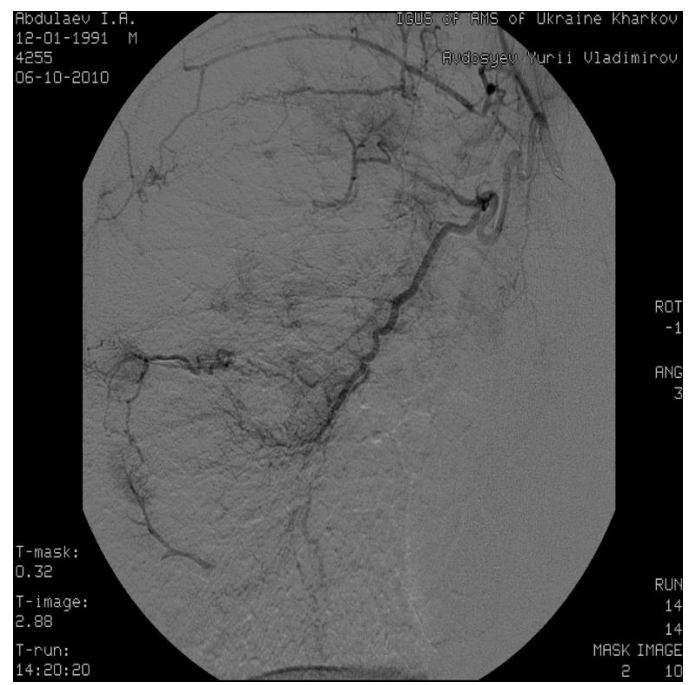

Fig. 1. Angiography of patient with bronchiectatic disease complicated by lung bleeding from bronchial artery

Classification of pulmonary hemorrhages proposed by Grigoryev E.G., 19831 grade - hemoptysis: 1a $-50 \mathrm{ml}$ per day; $1 \mathrm{~b}-50-200 \mathrm{ml}$ per day; $1 \mathrm{c}-200-500 \mathrm{ml}$ per day. 2 grade -massive 
pulmonary hemorrhage: $2 \mathrm{a}-30-200 \mathrm{ml}$ per hour; $2 \mathrm{~b}-200-500 \mathrm{ml}$ per hour. 3 grade - profuse pulmonary hemorrhage: $3 \mathrm{a}-100 \mathrm{ml}$ per saltum; $3 \mathrm{~b}$ - more than $100 \mathrm{ml}$ per saltum + obstruction of tracheobronchial tree, asphyxia. Classification depending on the extent of blood loss: 1. minor pulmonary hemorrhage - from 50 to $100 \mathrm{ml}$ per day; middle pulmonary hemorrhage - from 100 to $500 \mathrm{ml}$ per day; 2. severe pulmonary hemorrhage - more than $500 \mathrm{ml}$ per day; 3. extra severe, profuse pulmonary hemorrhage - more than $500 \mathrm{ml}$ per day; 4. bleeding arising per saltum or for a short period.

Small LB and blood coughing was detected in $15(18.8 \pm 2.2 \%, \mathrm{p} \leq 0.001)$ patients, medium and massive with highlight more than $200 \mathrm{ml}$ of blood - in $9(11.0 \pm 1.8 \%, \mathrm{p} \leq 0.001)$. Full treatment after REE of bronchial arteries radical no operation was possible in $2(0.47 \%)$ patients. Required complex examination of patients turned on a computer tomography of organs of the chest cavity and bronchofibroscopy. The use of these methods allowed pain most observations set side of defeat [24].

Upon identification pathologically effected BA (bronchial artery), by exercising neck their blood supply, in BA to the conductor as distally as possible a working catheter was inserted. A catheter was inserted through polyurethane emboli with a diameter 400-750 microns. Embolysis control on was carried out by contrast BA, revealed its stump and 40 lack of admission contrast substance in the distal sections [26]. With a pathological change in BA, increase in diameter, availability malformations polyurethane embolis, gelatine embolis combined with the introduction of microspirals whose use allowed to reliably close the extended BA test. With the powered by lung parenchyma view and the presence of clots in the respirator paths after roentgen-endovascular embolization of bronchial arteries carried out rehabilitation bronchofibroscopy combined with a short course antibacterial therapy and prescribe drugs to relieve pain [26, 27].

\section{Discussion}

The materials used by the specialized department of thorax of the SI «Zaycev V. T. Institute of General and Emergency surgery of NAMS of Ukraine». In accordance with the set tasks, complex clinical and laboratory, instrumental examination and treatment of 97 patients with pulmonary hemorrhages of different etiology were performed. After analysis of the obtained data from the examination and treatment of patients in the main group and the comparison group, it can be noted that properly organized conservative treatment of pulmonary hemorrhage using minimally invasive technology is, in most cases, quite effective and avoids severe, sometimes lethal, complications that are almost inevitable for surgery performed at the height of pulmonary hemorrhages (Fig. 2). Our studies have allowed us to determine the following indications for X-ray vascular occlusion in pulmonary hemorrhage: bronchi.

1. Pulmonary bleeding in inoperable patients with inflammatory diseases of the lungs and

2. Pulmonary hemorrhage in operable patients to stabilize the patient, in-depth clinical examination and reduce operative blood loss.

3. Pulmonary hemorrhage in limited fibrotic processes, clinical manifestations of which are expressed only by hemorrhage, and resection surgery is ineffective because of the possible risk.

4. Prolonged postoperative intra-pleural bleeding with undetected source localization, recurrent hemorrhages from operated lungs to preserve lung function and to prevent recurrent operations.

The absolute contraindications to the performance of radiographic occlusion were considered: cerebral coma, severe degree of hepatic-renal failure, unreliable catheter fixation in the vessel, incompatibility of the occlusive substances and anatomical features of the vessels to be excluded. The relative contraindications were pronounced intolerance of iodine-containing drugs, doubtful REO at high risk of intervention, age of the patient.

Among 45 patients with pulmonary hemorrhages, 37 (58.7\%) were treated only conservatively. One of the main components of conservative treatment of pulmonary hemorrhage in patients of the main group was artificial controlled hypotension, whose main purpose was to reduce the initial blood pressure by $30-40 \mathrm{~mm} \mathrm{Hg}$., which in turn reduced the intensity of blood loss and increased the effect of hemostatic drugs. 
Thus, the majority of patients admitted to the clinic with different types of pulmonary hemorrhages were cured by a complex of conservative measures without resorting to surgical methods of treatment. This group consisted mainly of patients with small short-term bleeding, which was not accompanied by a decrease in blood pressure and a decrease in the amount of hemoglobin (pulmonary bleeding I-II severity).

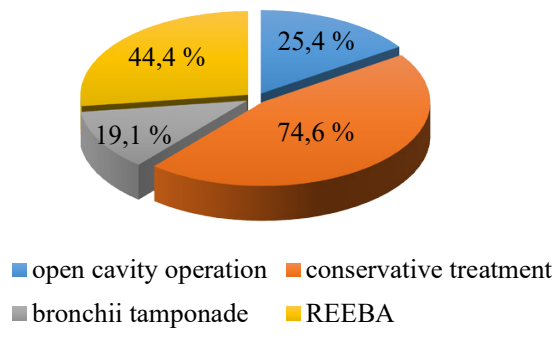

Fig. 2. Quantitative correlation of the results of conservative and surgical treatment in patients with lung hemorrhage

Our research suggests that bronchoscopic examination of patients with pulmonary hemorrhages is one of the leading and reliable diagnostic methods. The results of diagnostic and therapeutic bronchoscopies in 53 patients indicate the safety and high informative content of this study. In addition to diagnostic capabilities, we have used bronchoscopy to perform a number of therapeutic hemostatic manipulations, in particular, endobronchial occlusions. The bleeding bronchial obstruction, first allows stopping blood flow to a tracheobronchial tree, to avoid aspiration and inflammatory complications, and allows to carefully repair bronchial tubes and to provide improvement of ventilation of lung

In our opinion, endobronchial occlusion is an important step in the preoperative preparation of the patient. Due to the filling of the bronchus, it is possible to achieve a temporary discontinuation of the LB, which makes it possible to fully examine the patient, to determine the cause and source of bleeding, to correct disorders caused by the main disease and blood loss, to choose the optimal timing and type of further surgical treatment.

Bronchial occlusion in our observations was performed in $12(19.1 \%)$ patients and lasted from 5 to 7 days, the maximum term -9 days. We did not observe any complications in the form of exacerbation of the inflammatory process, respiratory failure or migration of the filling of the obturator in the airways. After removal of a filling in a bronchus local changes of a mucous in the form of its hyperemia and edema, which were inverse character, were noted.

In all $12(19.1 \%)$ cases, when the patient's condition allowed performing surgery, this technique made it possible, after correction of homeostasis in 3-10 days, to perform it with significantly less risk for the patient.

Bronchial arteriography and angiopulmonography are the most reliable methods of detecting the source of pulmonary hemorrhage, and therapeutic embolization of the bronchial arteries is one of the most effective, low-traumatic and reliable methods of stopping pulmonary bleeding. This method can be both independent and final, as well as the stage of preparation of the patient for further radical surgery. However, our studies have shown that endovascular interventions in the area of the bronchial arteries in the period of bleeding, especially profuse, are extremely complex and require careful training both from the operational and technical point of view, and in terms of preparation of the patient. In this regard, we propose to use the complex measures described above to temporarily stop the LC, including managed hypotension and bronchial filling, before conducting endovascular diagnostics. It provides a quiet, unlimited time, endovascular examination. Some authors consider the main cause of the BA cancellation in the first month after embolization others - not BA embolization, revascularization of the pathological focus with about the development of collaterals, progress congestion of the underlying disease.

The study was conducted in $34(53.9 \%)$ patients, with $32(50.8 \%)$ patients undergoing bronchial arteriography and 2 patients with angiopulmonography (3.2\%) with stopped bleeding. EBA 
was done to 28 (44.4\%) patients with COPD complicated by LB. The indication for embolization of the bronchial artery was the detection of direct or indirect signs of bleeding during angiography. In $13(20.6 \%)$ patients REO was performed at the "height of bleeding" due to inefficiency of conservative hemostasis. In 5 (7.9\%) patients, REO was performed after conservative hemostasis due to the high risk of recurrence of hemorrhage. In 4 (6.4\%) patients with bilateral inflammatory process and unspecified source of pulmonary hemorrhage at bronchoscopy, the technique of delayed embolization of bronchial arteries was used. All patients with unilateral localization of the pathological process after REO achieved a stable hemostatic effect. In the future, 14 (22.2\%) patients underwent routine lung surgeries within 4 to 10 days. 12 (19.1\%) patients of the main group were operated on and endovascular occlusion of the bronchial arteries was the main and definitive method of treatment of pulmonary bleeding [26, 27].

Mortality in the main group was $1.6 \%$ (2 patients with chronic lung abscess, which was complicated by profuse pulmonary hemorrhage). Patients for temporary hemostasis were performed REO of the left bronchial artery at the height of bleeding with subsequent pulmonectomy. Total recurrence of pulmonary hemorrhage was observed in $4(6.4 \%)$ patients. The ineffectiveness of conservative therapy in the comparison group served in patients with severe blood loss indications for external surgery - thoracotomy with lobo- or pulmonectomy. Planned surgical interventions were performed in $10(12.8 \%)$ patients, $14(17.9 \%)$ patients were operated on urgent at the height of pulmonary bleeding, and 54 (69.2\%) patients were treated only conservatively.

Out of the 36 patients in the comparison group, $5(6.4 \%)$ died, with a lethal outcome in the group of conservatively treated outbreaks in $2(3.7 \%)$ patients as a result of recurrent profuse bleeding, and $2(14.3 \%)$, among planned ones - 1 (10\%) patient. Total recurrence of pulmonary hemorrhage was noted in $16(29.5 \%)$ patients.

We have developed a patent of Ukraine for utility model UA 113048 (10.01.2017) "A method of treatment of patients with pulmonary hemorrhage", which includes catheterization of the femoral artery, as well as the obturation of bronchial arteries, which are performed by the introduction of rigid emboli in combination with microspiral. This technique was performed under angiographic control. We have developed an advanced technique and allows for an effective prolonged stop of pulmonary bleeding. The problem is solved by the fact that the obstruction of the bronchial arteries is carried out by introducing into them rigid emboli in combination with microspirals in the conditions of the angiographic department. The use of rigid emboli can block the bleeding vessel with elements of durable material that does not lose its shape under the pressure and influence of an aggressive environment. The combination of microspirals with emboli allows obtaining a dense conglomerate due to the partial penetration of the emboli in the microspiral, thereby realizing the moment of blocking of the bleeding vessel.

\section{Conclusions}

1. In our observations, no effective REE of bronchial arteries activity with repeated exposure of LB and hemoptysis observed in $10.2 \%$ of patients, early in $8.3 \%$ of them. Repeated LB at a later timing appeared in $13.5 \%$ of patients, which required repeated implementation of REEA. Causes of REE LB are different.

2. Roentgen-endovascular embolization of bronchial arteries is the method of choice for the treatment of LB and hemoptysis in most patients with chronic lung diseases. The use of REE in cancer lung complicated by LB requires further clinical evaluation developing clear evidence. Additional evaluation of the effectiveness of new embolizing materials.

3. Therefore bronchial artery angiography gives high efficiency in solving the problem of hemostasis in oncological and nonspecific lung diseases, for determination of localization and source of bleeding. Endovascular occlusion of bronchial arteries in pulmonary hemorrhage permits:

- to elaborate diagnosis because of the presence of specific angiographic signs of malignant tumor;

- to perform effective endovascular hemostasis;

- to gain time for stabilization the patient with the aim of planned surgical treatment. 


\section{Conflicts of interest}

No conflict of interest.

\section{References}

[1] Zener, R., Bottoni, D., Zaleski, A., Fortin, D., Malthaner, R. A., Inculet, R. I., Mujoomdar, A. (2017). Transarterial embolization of intralobar pulmonary sequestration in a young adult with hemoptysis. Journal of Thoracic Disease, 9 (3), E188-E193. doi: https://doi.org/10.21037/jtd.2017.02.82

[2] Hsu, C. C.-T., Kwan, G. N., Evans-Barns, H.,van Driel, M. L. (2018). Embolisation for pulmonary arteriovenous malformation. Cochrane Database of Systematic Reviews. doi: https://oi.org/10.1002/14651858.cd008017.pub5

[3] Kim, T. E., Kwon, J. H., Kim, J. S. (2014). Transcatheter embolization for massive hemoptysis from an intralobar pulmonary sequestration: a case report. Clinical Imaging, 38 (3), 326-329. doi: https://doi.org/10.1016/j.clinimag.2012.07.002

[4] Cardenas-Garcia, J., Feller-Kopman, D. (2018). POINT: Should All Initial Episodes of Hemoptysis Be Evaluated by Bronchoscopy? Yes. Chest, 153 (2), 302-305. doi: https://doi.org/10.1016/j.chest.2017.09.036

[5] Mohapatra, M., Mishra, S., Jena, P. (2012). Massive Hemoptysis in a Case of Intralobar Pulmonary Sequestration Associated with Pulmonary Hypoplasia and Meandering Right Pulmonary Vein: Diagnosis and Management. Case Reports in Pulmonology, 2012, 1-5. doi: https://doi.org/10.1155/2012/960948

[6] Ojha, V., Samui, P. P., Dakshit, D. (2015). Role of endovascular embolization in improving the quality of life in a patient suffering from complicated intralobar pulmonary sequestration - A case report. Respiratory Medicine Case Reports, 16, 24-28. doi: https://doi.org/10.1016/j.rmcr.2015.02.011

[7] Borzelli, A., Paladini, A., Giurazza, F., Tecame, S., Giordano, F., Cavaglià, E. et. al. (2018). Successful endovascular embolization of an intralobar pulmonary sequestration. Radiology Case Reports, 13 (1), 125-129. doi: https://doi.org/10.1016/ j.radcr.2017.10.003

[8] Bhargavi, V., Subbanna, I., Bangalore/IN (2018). Hemoptysis: an endovascular rescue. Available at: https://posterng.netkey.at/ esr/viewing/index.php?module=viewing_poster\&task=\&pi=142533

[9] Marcelin, C., Soussan, J., Desmots, F., Gaubert, J.-Y., Vidal, V., Bartoli, J. M., Izaaryene, J. (2018). Outcomes of Pulmonary Artery Embolization and Stent Graft Placement for the Treatment of Hemoptysis Caused by Lung Tumors. Journal of Vascular and Interventional Radiology, 29 (7), 975-980. doi: https://doi.org/10.1016/j.jvir.2018.01.773

[10] Depuydt, P., Soares, M. (2015). A bleeding problem in lung cancer patients. European Respiratory Journal, 45 (3), $601-603$. doi: https://doi.org/10.1183/09031936.00199914

[11] Fruchter, O., Schneer, S., Rusanov, V., Belenky, A., Kramer, M. R. (2014). Bronchial artery embolization for massive hemoptysis: Long-term follow-up. Asian Cardiovascular and Thoracic Annals, 23 (1), 55-60. doi: https://doi.org/10.1177/0218492314544310

[12] Ketai, L. H., Mohammed, T.-L. H., Kirsch, J., Kanne, J. P., Chung, J. H., Donnelly, E. F. ey. al. (2014). ACR Appropriateness Criteria ${ }^{\circledR}$ Hemoptysis. Journal of Thoracic Imaging, 29 (3), W19-W22. doi: https://doi.org/10.1097/rti.0000000000000084

[13] Sopko, D., Smith, T. (2011). Bronchial Artery Embolization for Hemoptysis. Seminars in Interventional Radiology, 28 (01), 048-062. doi: https://doi.org/10.1055/s-0031-1273940

[14] Mohapatra, M., Mishra, S., Jena, P. (2012). Massive Hemoptysis in a Case of Intralobar Pulmonary Sequestration Associated with Pulmonary Hypoplasia and Meandering Right Pulmonary Vein: Diagnosis and Management. Case Reports in Pulmonology, 2012, 1-5. doi: https://doi.org/10.1155/2012/960948

[15] Zener, R., Bottoni, D., Zaleski, A., Fortin, D., Malthaner, R. A., Inculet, R. I., Mujoomdar, A. (2017). Transarterial embolization of intralobar pulmonary sequestration in a young adult with hemoptysis. Journal of Thoracic Disease, 9 (3), E188-E193. doi: https://doi.org/10.21037/jtd.2017.02.82

[16] Ojha, V., Samui, P. P., Dakshit, D. (2015). Role of endovascular embolization in improving the quality of life in a patient suffering from complicated intralobar pulmonary sequestration - A case report. Respiratory Medicine Case Reports, 16, 24-28. doi: https://doi.org/10.1016/j.rmcr.2015.02.011

[17] Hosman, A. E., de Gussem, E. M., Balemans, W. A. F., Gauthier, A., Westermann, C. J. J., Snijder, R. J. et. al. (2017). Screening children for pulmonary arteriovenous malformations: Evaluation of 18 years of experience. Pediatric Pulmonology, 52 (9), 1206-1211. doi: https://doi.org/10.1002/ppul.23704

[18] Borzelli, A., Paladini, A., Giurazza, F., Tecame, S., Giordano, F., Cavaglià, E. et. al. (2018). Successful endovascular embolization of an intralobar pulmonary sequestration. Radiology Case Reports, 13 (1), 125-129. doi: https://doi.org/10.1016/ j.radcr.2017.10.003

[19] Balch, H., Crawford, H., McDonald, J., O'Hara, R., Whitehead, K. (2017). Long-term treatment outcomes of embolotherapy in pulmonary arteriovenous malformations in children with hereditary hemorrhagic telangiectasia. Ann Vasc Med Res. 2017, 4 (4), 1064. 
[20] Hosman, A. E., de Gussem, E. M., Balemans, W. A. F., Gauthier, A., Westermann, C. J. J., Snijder, R. J. et. al. (2017). Screening children for pulmonary arteriovenous malformations: Evaluation of 18 years of experience. Pediatric Pulmonology, 52 (9), 1206-1211. doi: https://doi.org/10.1002/ppul.23704

[21] Aydoğdu, K., Incekara, F., Şahin, M. F., Gülhan, S. Ş. E., Findik, G., Taştepe, İ., Kaya, S. (2015). Surgical management of pulmonary aspergilloma: clinical experience with 77 cases. Turkish journal of medical sciences, 45, 431-437. doi: https://doi.org/ 10.3906/sag-1401-165

[22] Alexander, G. R. (2013). A retrospective review comparing the treatment outcomes of emergency lung resection for massive haemoptysis with and without preoperative bronchial artery embolization. European Journal of Cardio-Thoracic Surgery, 45 (2), 251-255. doi: https://doi.org/10.1093/ejcts/ezt336

[23] Lanza, E., Muglia, R., Solbiati, L. A., Tramarin, M., Poretti, D., Pedicini, V. (2018). Emergency Transarterial Embolization in Postoperative Hip Bleeding: Indications, Techniques, and Results in a Retrospective Cohort. The Journal of Arthroplasty, 33 (7), 2273-2278. doi: https://doi.org/10.1016/j.arth.2018.02.005

[24] Pathak, V., Stavas, J., Ford, H., Austin, C., Aris, R. (2016). Long-term outcomes of the bronchial artery embolization are diagnosis dependent. Lung India, 33 (1), 3. doi: https://doi.org/10.4103/0970-2113.173059

[25] Samara, K. D., Tsetis, D., Antoniou, K. M., Protopapadakis, C., Maltezakis, G., Siafakas, N. M. (2011). Bronchial artery embolization for management of massive cryptogenic hemoptysis: a case series. Journal of Medical Case Reports, 5 (1). doi: https:// doi.org/10.1186/1752-1947-5-58

[26] Boyko, V. V., Krasnoyarujsky, A. G., Ponomarova, K. V., Khashina, V. A., Korolevska, A. Yu., Avdosjev, Yu. V. (2018). Surgical treatment in patients with pulmonary hemorrhages of various etiologie with used endovascular catheter system. European surgery, 50, S1, 1-118. doi: https://doi.org/10.1007/s10353-018-0526-0

[27] Boyko ,V. V., Ponomarova, K. V., Krasnoyarujsky, A. G., Korolevska, A. Yu., Avdosjev, Yu. (2019). Our experience of bronchial artery embolization in patients with pulmonary bleeding. European surgery, 51, 72. doi: https://oi.org/10.1007/s10353019-0600-2

Received date 15.10.2019

Accepted date 22.11.2019

Published date 30.11.2019
(C) The Author(s) 2019

This is an open access article under the CC BY license (http://creativecommons.org/licenses/by/4.0). 